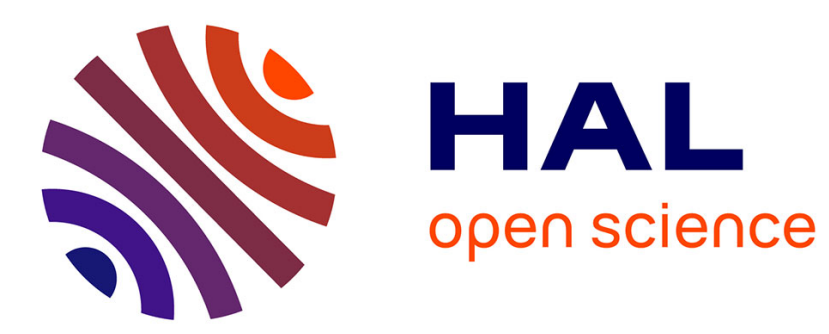

\title{
Innovation-Based Competition and the Dynamics of Design in Upstream Suppliers
}

\author{
Sylvain Lenfle, Christophe Midler
}

\section{To cite this version:}

Sylvain Lenfle, Christophe Midler. Innovation-Based Competition and the Dynamics of Design in Upstream Suppliers. International Journal of Automotive Technology and Management, 2001, 2/3 (Sp. Iss), pp.269-286. hal-00262522

\section{HAL Id: hal-00262522 \\ https://hal.science/hal-00262522}

Submitted on 8 Apr 2008

HAL is a multi-disciplinary open access archive for the deposit and dissemination of scientific research documents, whether they are published or not. The documents may come from teaching and research institutions in France or abroad, or from public or private research centers.
L'archive ouverte pluridisciplinaire HAL, est destinée au dépôt et à la diffusion de documents scientifiques de niveau recherche, publiés ou non, émanant des établissements d'enseignement et de recherche français ou étrangers, des laboratoires publics ou privés. 


\title{
Innovation-based competition and the dynamics of design in upstream suppliers ${ }^{1}$
}

\author{
Sylvain Lenfle \\ Assistant Professor \\ Université de Cergy Pontoise \& \\ Centre de Recherche en Gestion - Ecole Polytechnique \\ 1 , rue Descartes \\ 75005 Paris \\ \& Christophe Midler \\ Director of Research - CNRS \\ Centre de Recherche en Gestion - Ecole Polytechnique \\ 1 , rue Descartes \\ 75005 Paris
}

\section{Published in International Journal of Automotive Technology and Management, vol. 2}

n5, 2002.

\begin{abstract}
.
Although the evolution of the design process in car manufacturers and their first-tier suppliers has been studied extensively, the situation is different for upstream industries, usually chemical and steel firms. This article focuses on such upstream suppliers situation based on an interactive research with a major european steel-maker group, Usinor.

In its first part, it demonstrate that innovation-based competition is a significant issue for companies situated upstream from end-product manufacturers. The accelerating pace of the (re)design of end products downstream is increasing opportunities for the substitution of raw materials. The importance of this issue is obscured, however, by considerable inertia in the spread of innovations through the sector.

Then the article characterises the specificities of implementing an innovative design strategy due to the activity and position of the firm in the industrial chain. The conclusions will make it clear that design models developed for car-manufacturers and first tear suppliers are in many ways unsuitable for this different context. We finally propose 5 principles to evaluate and define a innovation management system in upstream suppliers.
\end{abstract}

Key words : innovation, management, design organisation, steel industry.

\footnotetext{
${ }^{1}$ Published International Journal of Automobile Technology management, (Inderscience) Vol 1 Nos 2/3, 2001, pp 269-286, 2001.
} 


\section{Biographical notes}

Sylvain Lenfle is teaching assistant at the Université de Marne-la-Vallée (France) and Phd student at the Centre de Recherche en Gestion of the Ecole Polytechnique. His research focused on innovation management in the iron and steel industry.

Christophe Midler is Research Director at the Polytechnique Management Research Center (Centre de Recherche en Gestion de l'Ecole polytechnique). He is also part time Professor in Ecole des Mines de Paris and in Marne la Vallée University. His research topics are project, research and design management, in relation with organisational learning theory. He has explored these topics in various industrial contexts : auto industry, construction, electronics, chemistry, pharmaceutics. His favorite methodology is long term interactive researches with firms.

L'auto qui n'existait pas, management de projet et transformation de l'entreprise, Dunod, 1993.

"Projectification" of the Firm : the Renault Case . Scandinavian Journal of Management, vol 11 n4 p 363-375, 1995 (Elsevier Science Ltd, G.B.).

Project as Arenas for Renewal and Learning (Eds in coll with R.A. LUNDIN) Kluwer Academic publication, 1998. 
Although the evolution of the design process in car manufacturers and their first-tier suppliers has been studied extensively, the situation is different for upstream industries, usually chemical and steel firms. At this level, how extensive are the repercussions of innovation-based competition, which is so important on markets for end products? Are the new design models being developed by manufacturers suitable for the specific situation of upstream companies ? If not, is it possible to formulate a specific design model for upstream firms, and what is its relationship to previous models?

To answer these questions, two studies were carried out with typical upstream firms: the chemical and pharmaceutical company Rhône-Poulenc (Charue-Duboc, 1997, 1998, CharueDuboc et Midler, 1998) and the steel-maker Usinor. This article is based on the second study which is going on since 1997.

First, an in-depth ex post analysis was made of several projects. Then, in real time, we took part in a major on-going project, in order to test the new methods and tools developed for these situations.

The main themes we will develop in this article are:

- Innovation-based competition at the level of end products is also a significant issue for companies situated upstream from end-product manufacturers. The accelerating pace of the more or less radical (re)design of end products downstream is increasing opportunities for the substitution of raw materials, as part of the never-ending search for compromises. The importance of this issue is obscured, however, by considerable inertia in the spread of innovations through the sector (concept of the endangered dominant firm, Boudès, 1997).

- Implementing an innovative design strategy poses problems that are specific to the activity and position of the firm in the industrial chain. Our analysis of these characteristics of innovative upstream solutions will make it clear that design models developed in manufacturing are in many ways unsuitable for this different context.

- Finally, we propose 5 principles to evaluate and define a innovation management system in upstream suppliers. These principles are supporting the ongoing experiments in Usinor on a major innovative project of the firm. A key point is accelerating and guiding the process of acquiring knowledge about upstream innovative solutions. 


\section{The importance of innovation-based competition for upstream industries: the} example of the steel industry

This section will show that innovation-based competition does not affect the manufacturing sector alone. On the contrary, upstream firms are also required to innovate, notably through pressure from the manufacturers themselves. Yet, as we shall see, the position of upstream firms in the industrial chain and developments in their customers' design processes put them in a vulnerable situation of "hidden urgency".

\subsection{Innovation against the slow erosion of a dominant position}

The "innovation imperative" for firms like Usinor is rooted in the combination of two trends.

First, the rise of competition from the newly industrialized countries is eroding the traditional advantages of Western firms (technological monopoly on "major processes", the impact of size, etc.). This pushes such firms to concentrate on high value-added products, a strategy that requires a capacity for constant innovation. The case of Usinor is especially typical of this trend, as the firm has steadily moved away from "standard" activities (particularly long products) to focus on high value-added steels (carbon steel plate and stainless steels), which are more profitable.

Second, manufacturing firms are constantly widening their search for breakthroughs that would enable them to develop more competitive products, which leads them to call the use of traditional materials into question. To stay with the example of Usinor, steel is the basic material par excellence on the company's main market ${ }^{1}$, automobiles. Steel accounts for $55 \%$ of a car's total weight. Its success is due to its mechanical properties, its low cost (compared to potential substitutes like plastics and aluminium) and the considerable existing investment and know-how accumulated over decades of experience. However, this situation could change in the coming years due to the growing importance of reduced weight. On the one hand, higher safety standards and the increasing sophistication of cars have led to a steady increase in cars' weight over the last few years. On the other, government antipollution standards ${ }^{2}$ entail the lightening of vehicles (or the acceptance of poorer performance, which is not easy in today's markets). These two trends are encouraging radical changes in the design of the next generation of cars, which could challenge existing 
compromises and technical solutions. This might well leave steel in a much weaker position in some of its most profitable market segments. The increasing use of substitute materials is already apparent on some cars, and this trend should continue: aluminium (body, doors and boot), plastics (fenders ${ }^{3}$, floors), magnesium (body parts, seats, dashboard, etc.), and so on.

To counter this process of erosion, the steel maker must make substantial outlays for research in order to offer ever more effective solutions. This research should involve not only the products themselves (high-strength steels, coated steels, TRIP steels, tailored blanks ${ }^{4}$, etc.) but also their implementation (forming and assembly) and even software that enables the automobile designer to find an optimum "steel solution" to meet the specifications of a piece or a function.

We should emphasize the difficulties of this strategic situation, where increased outlays for innovation are due not to the prospect of solid growth (as, for example, in other recent examples like personal computing and the Internet) but to the necessity for halting a decline that would otherwise be inevitable.

\subsection{The hidden urgency of innovation in endangered dominant firms}

Another difficulty affecting innovation in this area is related to the significant inertia in the design chain between the decision to apply an innovation in materials and the product's appearance on the market. One consequence of the new development approach of downstream manufacturers is to limit as much as possible any uncertainties associated with breakthrough technical innovations in the course of developing a new product. Deadlines for the upstream supplier are thus shortened, while the real economic impact of these decisions is still very distant. Thus, given the leadtimes inherent in manufacturers' design processes, technical choices for vehicles to be produced in 2004 are being made at the end of 1999. If innovations are not sufficiently advanced to interest the customers in this very narrow "target window”, an entire generation of vehicle manufacturing will be lost, with the risk of making the situation irreversible ${ }^{5}$.

The problem is thus one of mobilization and incentive to deploy the effort needed to meet an urgent strategic need when the actual economic returns are so remote. The importance of speed, a feeling of urgency and the risks of the situation stand out more clearly in other contexts where design cycles are shorter. Here there is no question of "reacting to a market stimulus”, because such reactions will already be much too late. The same problem 
can be seen in the pharmaceutical industry: competitive advantage can depend on a difference of a single week in submitting a patent application, while the products will be marketed at least ten years later! The difficulty in grasping the urgency is heightened when, as here, the company is in a dominant position (Boudès, 1997) and when the exploration of potential breakthroughs diverges from solutions envisaged by the company in the short term.

Innovation is thus an imperative for upstream firms as well, even if this is less apparent than in the manufactured goods sector. This does not, however, imply that the organizational solutions that come to dominate product design in sectors such as automobiles and electronics are adaptable or relevant to the upstream context. The next section describes the specific features of a strategy for innovative upstream services. We will also discuss the relevance and limits of organizational forms for design that have been developed recently in other contexts. In the final section, we will outline a method for managing a project portfolio for innovative upstream goods and services that takes these specific features into account.

\section{The specific features of managing strategies for innovative market supply in the}

\section{situation of upstream firms}

In this section we will describe what is involved in supplying innovative goods and services in the context of upstream firms. Five specific features stand out, which we will compare with the situation of managing new products in the manufacturing industry: defining the scope of the innovation process; pushing technological innovations into the value chain in the search for markets; the number and size of projects; a strategically complex situation; and a high level of uncertainty. We will study the problems each of these poses for the transposition of the most widely used project-management models to the case of upstream firms.

\subsection{The complexity of defining innovative upstream solutions}

The first specificity relates to the very nature of the firm's activity. In manufacturing, the design process has a clear, though not necessarily simple, end result: a new, tangible product with an identifiable performance and sales, such as a line of cars, a bridge, an 
aeroplane, etc. In the case of upstream companies, however, the outcome of the innovative process is more difficult to define.

In the recent period, one of the main strategic approaches of big upstream firms like Usinor has been, as we have seen, to abandon this concrete definition of their economic activity (which would make them mere "sellers of tonnes of steel”) and replace it with a definition involving comprehensive service supply to downstream industrial customers, i.e. offering a "steel solution” (Benghozi, 1999). This refers to the firm’s capacity to mobilize an in-house knowledge base and capacity to attack a problem which is functionally defined by the customer, such as designing a steel auto body part able to absorb the impact of a frontal shock, to support certain mechanical parts and to absorb certain vibrations, within given limits on space, weight and cost. The same evolution has taken place in the world of chemicals, with the change in Rhône-Poulenc's strategy from commodities-oriented chemistry to chemistry based on function or "use value" (Charue-Duboc 1998): the actual steel or chemical product sold is secondary to its function in the specific assembly manufactured by the customer for integration into the end product.

This redefinition of firms' activity, the economic rationale for which is examined above, raises problems when we try to define a policy for innovative market supply, for two reasons.

- First, it considerably expands the scope of the work involved in developing an innovation.

Consider a project for the automobile market that we have been involved in for three years: the development of hydroforming, a new forming process ${ }^{6}$. In this example, a narrow vision of the project would involve producing samples and would end with the entry of the corresponding products into the catalogue, leaving it up to the customers to define and develop any applications. With a broader view of the firm's vocation, the project should take responsibility, together with the customer, for the application aspect, and hence for defining services associated with the use of the new material or process (and thus supplying the entire design and manufacturing process for a part using the innovation).

- Second, the broad scope involved in innovative market supply, and thus the outcome of innovation projects themselves, are difficult to define. On the one hand, the project is closely linked with applications developed by the customers, such as supply of a piece of hydroformed tube, to continue our example. The value of the project for the upstream firm would thus be defined by the sales generated by the steel in this piece. On the other hand, 
producing a single piece is not an end in itself for this kind of project. Rather, the goal should be to supply a generic process-material solution, less contextualized than the piece itself - a "generic solution”, "proven concept” or "semi-product” (Weil, 1999) that can be quickly applied to the design of other applications. Without this perspective, the investments required would not be profitable. As a result of this goal of standardization and the inertia of the process, the total sales figure gives only a very incomplete picture of the project's achievements.

It is well known that clear perception of the potential gain from projects to design new products, undertaken with a view to actual production of the product at a given date and with given resources, is a powerful motor for energizing development projects. However, management of the design of upstream products cannot count on this mechanism due to the relatively abstract and diffuse character of the results and the stakes involved.

\subsection{Technological innovations "pushed" into the value chain in search for markets}

Innovation results when a potential need finds a response, generally based on the use of a new technology. The initial contribution of the upstream firm in this process is obviously based on its knowledge of the relevant materials and technologies. Exploration of the technical aspect can thus be handled within the firm. In contrast, a detailed awareness of the functional specifications that are of value on the market for end products essentially falls within the purview of the chain of downstream customers that process the supplied raw material, even though companies like Usinor have significantly developed their capacities in this area. This detailed awareness of needs is clearly crucial to designing an innovative "materials solution". Continuing with our example, Usinor could carry out an in-house study of the technical feasibility of a hydroformed part, but it is the auto makers who follow all developments in vehicle manufacturing, who thus can determine the parts for which these technologies might have advantages over existing technologies, and who can precisely define whatever specifications must be met. This involves determining the compromises needed among specifications that are usually not convergent and anticipating the direction and pace of changes in expectations based on the potential moves of other materials competitors in order to determine the performance required. Access to this knowledge is thus essential if the upstream firm's research is to be more than a blind trial-and-error process. This is the reason 
for the rising importance of occupational specialities involved in the search and the codification of this knowledge (Charue-Duboc, 1998), and for the involvement of customers in these projects.

One of the difficulties of this strategy for chemical and steel-making firms is that, unlike manufacturing firms, they are often situated very far from the end user, frequently separated by several stages of materials processing and distribution. This has two consequences.

- First, the "customer system" whose choices need to be understood is complex, as it must integrate all the processing stages up to the end product. This amounts to an organization or even an organizational complex ${ }^{7}$. For a hydroformed item, for example, it is necessary to take into account not only the engineers who designed the vehicle parts, but also the designers, methods, welders, paint, etc. If the item is made by a supplier (as is usually the case for components like exhaust lines, tanks, etc.), the supplier's situation must also be integrated. It is necessary to understand the needs and constraints of each actor in the process.

- Second, setting up co-design partnerships is more difficult for upstream firms than downstream ones. In the manufacturing sector, the initiative for "design revolutions" comes from the end firms in the chain. They are able to compel their suppliers to use a concurrent engineering approach by wielding their power as buyers. The situation is obviously different for upstream firms, as projects usually require co-ordinating downstream customers or specifiers rather than upstream suppliers. How can customers be convinced to take part, when, as is usually the case, it is not possible to exercise financial leverage over the downstream part of the chain?

Bansard, Cova and Flipo (1992) answered this question by showing the importance of distinguishing among situations on the basis of who initiates the innovation process: the customer, by expressing a demand, or the supplier, by offering innovative goods and services. 
Figure 1: the various configurations of initiative in customer-supplier co-design

\begin{tabular}{|l|c|c|c|}
\cline { 3 - 4 } \multicolumn{2}{c|}{} & \multicolumn{2}{c|}{ Supplier } \\
\cline { 2 - 4 } \multicolumn{2}{c|}{} & $\begin{array}{c}\text { Anticipation } \\
\text { Proactive supply strategy }\end{array}$ & $\begin{array}{c}\text { Reaction } \\
\text { Satisfaction of a demand }\end{array}$ \\
\hline \multirow{4}{*}{ Customer } & $\begin{array}{c}\text { Anticipation } \\
\text { Expression of a } \\
\text { need }\end{array}$ & (III) & (I) \\
\cline { 2 - 4 } & $\begin{array}{c}\text { Reaction } \\
\text { Response to } \\
\text { the supplier's } \\
\text { offer }\end{array}$ & (II) & \\
\hline
\end{tabular}

Source : adapted from Bansard, Cova and Flipo, 1992.

Involving the customer will be relatively easy whenever the firm is in a situation corresponding to the first row of the figure 1, when the customer is motivated by an explicit need (situations I and III), whereas it will be more difficult for projects in situation II (the last situation being ignored because it does not lead to the development of an innovative process). In a study of automobile equipment makers, Lamming (1993) differentiated two strategies for the supplier (corresponding to the columns) in these situations, which he described as either “a loyal collaborator" or a "key partner”. The first corresponds a "customization” strategy driven by the customer (in terms of methodology, this involves adopting a design model suited to the customer's specific approach; in terms of content, it involves specifically adopting the unique specifications of the customer for the component to be supplied). The second corresponds to a supply-side strategy based on technological product and process strategies (technical strategies for the component, economies of scale so as to reduce costs but limiting the differentiation offered to builders, etc.). The choice between these two strategies (Donada, 1998) and the organizational mechanisms needed to handle the continual tension are key to the effectiveness of the design model for first-tier suppliers (Kesseler, 1998).

The strategies studied at Usinor and Rhône-Poulenc fall into the proactive categories of "key partners". In this case, the ideal is to be situated in class III, where explorations of a need and a technical potential converge. Moreover, the existence of an expressed demand is often a significant criterion in formal tools for choosing projects. However, eliminating typeII situations will have little chance of halting the erosion we have described. Innovation 
strategies are being implemented in a competitive environment. With regard to clear trends such as the lightening of vehicles, if competitors (e.g. aluminium firms) are able to develop interesting proposals before the customer has formulated a precise demand, these are likely to impact heavily on the way the customer formulates the problem, thus giving such competitors a head start. Anticipation is a key word in today's competitive climate. Thus, starting from a situation in which the supplier is exploring and anticipating customers' latent requirements (type II), the goal is rapidly to elicit an explicit demand that will then lead to co-designing (type III).

\subsection{A profusion of small emerging projects}

Whereas an auto maker handles several big development projects that are vital for its survival, a company like Usinor manages several dozen projects at a time. There are numerous outlets for the products of chemical and steel-making firms. A given steel will be used for automobiles, construction, household appliances, etc. Consequently, project management is characterized mainly by an abundance of innovation paths, and hence of projects.

The large number of projects makes it difficult to implement "heavyweight" project management. It is easier to dedicate full-time experts to projects that reach a certain "critical mass”. When the company needs to manage several dozen projects, it is almost impossible to assign full-time personnel to each, whether project leaders or team members. In these circumstances it is not unusual to see the same person manage several projects and take part in the work of other teams, with predictable consequences for timetabling. In the majority of projects studied, project leaders combined a managerial post with the leadership of a project, or more often several projects. As a result, they were able to devote only $10 \%$ of their time to the project concerned, and other team members were in the same position.

In this situation, the problem of choosing among projects is crucial, and this brings us back to the process of project portfolio management, which is the only means of obtaining a sufficient concentration of energy and resources (Cooper et al. 1998, Bayart et al 1999).

\subsection{Great strategic complexity}

This question of choosing projects is related to an a priori assessment of the potential gains. This is a matter of determining whether an idea for a product having use value for end 
customers will result in a profit for the company. For several reasons, the answer is anything but easy.

First, the novelty of the ideas makes forecasts risky (remember that, in the case of automobiles, this is occurring about five years before the end product is marketed, if we take into account the duration of both the upstream project and development by the customer).

Second, competition is not stable. Many of the projects studied went through sharp turns due to strategic events, such as the sale or purchase of business, a joint venture that was blocked or was not planned from the outset of the project, etc.

Finally, an understanding of the potential gain from a project depends on how well it fits the firm's structure. On the one hand, the practice of attaching personnel to a central research unit is often criticized as cutting them off from the real situations of customers. On the other, attaching them to a customer- or product-based business unit has two disadvantages. First, an understanding of long-term issues is more tenuous at this level, which is accustomed to employing short-term, highly operational criteria. In the choice between mobilizing energy to produce and sell existing products, or mobilizing knowledge and expensive equipment to test tomorrow's products, priority is usually given to immediate needs. Second, the potential gain from a project can be transversal, cutting across several markets. Without consolidation, the perception of the project's importance can thus be diluted at different levels of the organization.

\subsection{Projects with a significant research aspect, and thus a high risk of being stopped}

Building a package is the chief characteristic of projects in the manufacturing sector. This generally involves capitalizing on existing scientific and technical research by selectively integrating the products of such research. Some learning must occur, particularly regarding knowledge of interfacing (Weil, 1999), but the level of uncertainty is nonetheless not dramatic. In contrast, the projects of the chemical and steel-making firms described here are typified by much more striking changes and unknowns. Technically, the transition from a stamped to a hydroformed part involves the entire design chain. It is necessary to determine whether its form can be achieved in the new material and to study its mechanical, acoustic, and ageing properties, as well as its reactions to the different processes that it must undergo. 
Economically, there is significant uncertainty regarding costs, given a situation where the industrial scenarios exist only on paper. This high level of uncertainty has two consequences:

- First, there is a much lower probability that such parts will ultimately find their way to the market for end products. This explains the culture of caution which has taken root in this situation. Given the lower likelihood that the product will ever be marketed, firms hesitate before undertaking more extensive research which, if unsuccessful, will be a lost investment. This culture makes it difficult to implement the principle of anticipation so omnipresent in the approach of modern design. This has all too familiar consequences, such as projects that spiral on and on; although they do not immediately use many resources, no-one knows whether they will eventually produce any results. Just how far is the principle of anticipation applicable, and how is it possible to break this vicious circle in which the likelihood of success remains low because no-one dares to anticipate?

- Second, unlike a conventional development project, which largely amounts to the realization of an object and an industrial process, here the management of knowledge is dominant. A vast field covering potential outlets for the technology and its technical properties must be explored as fast and thoroughly as possible. The production of a part is thus only a partial result of the project and should be considered as helping to mark out the field of application of the new material, since the extent of this field is initially unknown. The effectiveness of project management is comparable to the effectiveness of the process of creating knowledge or learning. In this regard, the study of such processes should draw on work on the concepts of collective learning and knowledge management in organizations (Midler, Charue-Duboc, 1998, Nonaka et Takeuchi 1995, Lundin et Midler 1998, Hatchuel, 1999, Hatchuel et al.,1999).

Given these five specific features, the model of concurrent engineering as it has developed in the manufacturing industry could be adopted only with great difficulty, even though its principles are generally relevant. The issue for current research is to develop a management model adapted to this particular situation.

\section{Towards a design model suitable for innovative upstream product supply}

This section concentrates on the characterization and management of projects for innovative product supply, which has been the focus of our current research at Usinor. 


\subsection{Defining the space for exploring projects for innovative upstream goods and services}

The notion of a project is polysemous and thus very ambiguous. Here, the term “projects for innovative goods and services” refers to projects with three characteristics:

1) they are initiated by the supplier even when explicit customer demand does not necessarily exist (categories II and III of Table 1);

2) instead of a single product, they propose generic concepts (target application/technical solution) upstream from development projects;

3) as a result, they simultaneously explore the characteristics of the technical innovation and its potential applications and use value for the customer(s).

A company like Usinor obviously deals with other types of projects (we are tempted to say "fortunately", since the category under discussion is inherently problematic), including the improvement of existing products with no significant technical breakthroughs, the development of a new "steel solution” to meet a customer's precise, explicit specifications (for example, a wheel with certain functional characteristics, a target cost, etc.), the launch of a new production line, etc. However, in the current context of innovation-based competition, projects for innovative solutions are of crucial significance for a company’s future.

A project for innovative goods and services is thus a space for exploration having, first, a technical aspect, and second, an applications aspect. To explore these two dimensions, the team will define and carry out physical tests and simulations while approaching clients to propose joint development of products incorporating the innovation. The project can thus be formalized as a series of experiments or studies making it possible to acquire knowledge about the innovation and, if the customer studies go well, eventually generating sales. The project team must thus build and traverse the space outlined in Figure 2 below. 
Figure 2 : the project journey

\begin{tabular}{|c|c|c|c|c|}
\hline $\begin{array}{r}\text { Field of knowledge to be } \\
\text { explored } \rightarrow \\
\text { Space for learning vectors } \\
\downarrow\end{array}$ & Feasibility & Process & $\begin{array}{l}\text { Functional } \\
\text { behaviour }\end{array}$ & $\begin{array}{l}\text { Potential } \\
\text { sales of } \\
\text { hydro- } \\
\text { forming }\end{array}$ \\
\hline \multicolumn{5}{|l|}{ Experiment 1} \\
\hline \multicolumn{5}{|l|}{ Experiment 2} \\
\hline$\cdots$ & & & & $\ldots$ \\
\hline \multicolumn{5}{|l|}{ Customer A study } \\
\hline Customer B study & & & & \\
\hline
\end{tabular}

The hydroforming project can be used to illustrate this design description. The firm's interest in hydroforming began in 1994 following a one-off discussion with a customer in the automobile sector. A series of contacts (customers, exhibitions, competitive steel makers, press manufacturers, etc.) and articles in the trade press indicated that this could be a technique of the future for various industries, including automobile manufacturing, which is a key market for the firm. A study was thus launched to identify existing product world-wide, any a priori advantages of hydroforming, suppliers of presses, etc. Given the low level of technical knowledge on the subject, the company decided to invest in a hydroforming press. A project team was set up and given charge of developing this new procedure.

This is clearly a project for innovative goods and services. Indeed, once the press was installed, no customer really expressed a demand for this technique, although a few expressed interest. Similarly, the real potential of the procedure was unknown. The team's task was thus to develop Usinor's knowledge so that it was in a position to set specifications ${ }^{8}$ for a technical innovation and to offer steel solutions meeting the long-term requirements of its customerpartners. The "result" of the project was indeed the generation of "generic" knowledge about hydroforming, knowledge that will make it possible to develop various specific applications.

To achieve this kind of result, it is necessary to understand and master the technology while discovering its potential applications. The team should thus simultaneously define and carry out a research programme ${ }^{9}$ and contact customers to carry out joint studies ${ }^{10}$. The interaction between these two aspects will make it possible: 
1. gradually to resolve technical uncertainties (what are the real possibilities of deformation? is the process truly robust? etc.);

2. and to identify the most relevant applications (which items? with which functional characteristics? etc.).

This challenges the traditional separation between research and development. Research is needed to determine relevant applications, and at the same time case studies raise basic questions. Bringing these two aspects together makes it possible for the team to advance. What remains is the matter of managing this process and dealing with the back-andforth between generic knowledge and specific cases.

\subsection{The basic activities involved in exploration: management of knowledge and production of probes}

Schön $(1983,1997)$ described the combination of the processes of abstract knowledge and action using the metaphor of a "conversation with the situation". On the one hand, the designers' knowledge enables them to formulate problems that lead to preliminary answers, and thus to tests and action plans. On the other hand, implementation of these action plans and attempts to implement these answers constitute a test that leads to new knowledge - the situation "responds" to the designers, often in a surprising way. The designers then make use of this new knowledge to shift the exploratory path towards other fields, revise the starting framework, or even attempt to transform the situation. In this sense, the probe, as both an action and a knowledge-generating event, plays a central role in the design process, a role different from the traditional validation of scientific statements. Hatchuel (1999) formalized this transactional knowledge-action process under the terms of rationalization strategies and "learning from doing”, explicitly taking into account the collective character of the investigation.

The probe is thus the key activity in the exploratory process. Its value depends on both the extent to which it increases knowledge and the extent to which it constitutes an advance in implementation. Its importance is emphasized by researchers working on companies facing highly dynamic technology/market environments (Lynn, Morone and Paulson, 1996; Brown and Eisenhardt, 1998). A comparable emphasis can be found in the concept of an "event" in Zarifian (1995), with the - essential - difference that the latter highlights the fortuitous 
dimension of chance, which is contrary to the design strategy: a surprise coming from a designer is - even if this expression appears paradoxical - an intentional and expected surprise, brought about by the overall design strategy itself.

The fact remains that the "production" of probes is an organizational problem. Studies of the activity of research laboratories in the fields of sociology (Latour, 1989) and management (Charue-Duboc and Midler, 1998) reinforce our observations of the inexorable intermingling of the intellectual and material dimensions of research activity. On the one hand, it is necessary to develop a research programme (formulate a hypothesis, choose the tests to carry it out, etc.), to analyze the results, formally to describe the phenomena observed, etc. On the other, it is necessary to produce samples, conduct the tests (the supply of raw materials, the preparation of equipment, etc.) and carry out the calculations, etc. This second dimension is often neglected by stereotypes of ivory tower theoreticians. It nevertheless plays an essential role when the generation of knowledge mobilizes machines as sophisticated as a hydroforming press and, since the project is taking place amidst a sharp division of labour, involves the co-ordination of dispersed teams.

Organizing a probe as part of a research programme is much more complicated than it might appear. First it must be set up, which involves deciding on a goal, the materials to be used, parameters for running the machine, and the variables measured. Then it must be organized, which means finding a technician and available testing equipment (knowing that this often involves rare resources), obtaining the supplies needed, and so on. Then comes the tricky stage of analysis. The researcher once again must seek out a technician, measurement tools, and so forth. All this can take many working hours. Moreover, this process can be delayed at every stage. For example, new materials needed to verify a hypothesis may not be immediately available; in this case, it will be necessary to modify a production schedule (rolling, tube production lines, etc.) on a production site that is often far away, which could delay the process for several weeks.

This picture gives a sense of the difficulty of running projects for innovative upstream goods and services. Organizing probes to learn about innovations actually forms part of the client-supplier relationship. Before returning to these points in the conclusion, we will present the principles that could serve to underpin a system for managing these projects. 


\subsection{Principles for managing innovative upstream market supply}

The analysis presented above allows us to lay down certain principles to be used in evaluating a system for organizing innovative upstream goods and services.

\section{Principle 1: the specificity of the basis for evaluation}

The first step in assessing performance or implementing a strategy is to define an observer, that is, a reference base. We have seen that it is usually difficult to grasp the importance of projects for innovative goods and services using established frames of reference. The advantages they can bring usually lie outside existing horizons; they cut across the boundaries of existing markets; they have non-linear effects which are generally poorly understood. Evaluating the project therefore cannot be separated from creating a context that will serve as the project's frame of reference. To a large extent, discussing the project involves discussing the advantages to be derived from this potential context and then creating it.

\section{Principle 2: the dual role of research for innovative upstream goods and services}

Every investigation (research report, customer study) associates a process of generating knowledge with a process of creating sales. A management scheme must thus take into account these two different dimensions of performance. A study could lead to new sales without contributing any new knowledge other than the existence of a particular market for the item. Conversely, a study could fail to generate any sales but produce knowledge that is crucial for understanding a technique or defining its potential field of application. This makes it possible to improve the investigation's results upon each iteration. As knowledge accumulates, technical uncertainties are reduced, the tests to be conducted and the potential applications are more precisely known, and step by step the two dimensions converge - or the investigation is halted if the technique proves to be less valuable than anticipated.

\section{Principle 3: the centrality of testing in the management scheme}

Testing is the value-added activity par excellence for the two dimensions of performance. The study of the hydroforming project shows that testing takes various forms:

- internal (feasibility, forming, assembly, productions, etc.) or external (functional behaviour test, mass production test) physical tests; 
- simplified representation of the products/process under study (simulations, test models, etc.);

- meetings and discussions with partners (other steel makers or suppliers) and/or competitors;

- presentation and discussion of the results with the customer;

- summaries for company personnel not involved in the project, etc.

All these tests should have three features which are conducive to knowledge creation:

1. they represent a test of the "theory in use" (Argyris and Schön, 1978) by the personnel involved in innovation, thus leading them to consider the relevance of their current research and, if necessary, to carry out new tests or even completely revise their understanding of phenomena involved (“double-loop learning”, ibid.).

2. they require those involved to formalize their knowledge, to make it explicit (in the sense used by Nonaka, 1995) so as to present and/or evaluate it. For example, meetings with customers "reveal the weaknesses of studies and encourage [those involved] to seek new responses" ${ }^{\prime 11}$.

3. they make it possible to mobilize the energy of everyone involved (both within and outside the team) for explicit, key deadlines.

We believe that these tests should be the basic work unit of the management scheme. The intensity of learning will depend on the team's capacity to generate, conduct and exploit a continuous flow of tests over a period of time. There should be an effort to accelerate the production of tests, even if this proves difficult (section 3.2.)

\section{Principle 4: the reversibility of the investigation}

Principle 4 states that the lessons learned from a given study should be able to serve in a different framework. Investigation is carried out in two arenas: that of user functionality and that of technical properties. In attempting to satisfy a specific customer demand, researchers may make technical discoveries that would be useful elsewhere. Discoveries resulting from the work on this demand could also lead to revising the initial technical hypothesis that led to carrying out the study. In a typical example, a search for outlets for hydroforming yields a solution using tailored blanks, or a study of hydroforming an item reveals that this technology has interesting properties that could be used on other items. The management scheme must enable and even promote such heuristic approaches. 


\section{Principle 5: giving the investigation a temporal focus}

Projects for innovative goods and services take place in an extremely dynamic competitive environment. Use values, strategies and technologies are changing even as they are being explored. Responses that are satisfactory at a given moment are no longer so a brief time later, since the questions are changing even as they are being studied. Handling different investigations sequentially thus increases the risk that a partial response at a given point will no longer be satisfactory once the problem's other dimensions have been resolved. The project would thus be perpetually out of control. The likelihood that the project will yield results thus depends on the speed of exploration and the synchronization of the market-based and technical dimensions of the solution.

A project should be considered as a portfolio of studies (techniques, developments with customers emphasizing different functions, etc.). Based on this principle, an investigative strategy that planned all these studies simultaneously would be much more valuable than one that programmed them in succession. This has echoes in the notion of concurrent engineering, but here the goal is not so much to shorten time-to-market (a key argument in developments with low uncertainty) as to increase the likelihood of success (desynchronizing the "technical" and "market" dimensions increases the risk they will never converge). As in the field of projects for "conventional” new products, the application of this principle generally conflicts with the logic of resource management, which seeks to smooth out workloads. Under this principle, a project consumes significant resources at the outset, but can be halted abruptly once it becomes (rapidly) certain that the innovation is not promising in the current context. This makes it possible to avoid projects that consume resources without ever showing results and wind up wearing out both researchers and their managers.

\section{Conclusion: towards the rationalization of projects for innovative goods and services}

This article has emphasized the importance of innovation-based competition in upstream companies. At the same time, we have described the specific features of design situations in this area (Midler, 1996) and explained the principles for managing what we have called projects for innovative goods and services. We will conclude by showing how these principles can be translated into practice and what kind of obstacles will be encountered during implementation. Our current research, in the context of organizational experiments 
carried out on the hydroforming project, has focused on three fields, in which we have sought to apply the principles set forth above:

1. Managing in-house learning about the technology. We have demonstrated the often poorly understood importance of the "productive" aspect of research, which is often treated as a purely intellectual scientific activity. Saving time in this area can accelerate the generation of knowledge through more frequent testing of the "theory in use". This takes us back to, among other things, methods for encouraging actors who are not directly part of the project team but whose contribution is nevertheless essential for its proper functioning (supplying all kinds of materials, internal "sub-contracting” of the study, etc.).

2. Customer/customer-supplier relations. The cases we have had the opportunity to follow point up the difficulty of carrying out co-design on highly innovative subjects. Comparing the functioning of several studies indicates several elements that could help avoid loss of control in development: the existence of a temporal framework fixed ex ante, the technical and policy competence of company representatives, the involvement of the two parties, the use of simple tests to validate different search paths, etc.

3. Overall management of the project. Since innovation involves bringing together a requirement (often latent in our cases) and technical knowledge (under development), it is essential that a permanent link be established between customer studies and internal learning about the technology. This raises organizational questions (for example, the existence of a project leader) but also the issue of which management tools should be used to monitor the various kinds of studies (internal and external), to determine the resources and energy needed according to an assessment of their importance, and to capitalize on the learning acquired about the innovation.

For about ten years now, changes in the design process have been reaching new sectors and contexts. Each time, this process of collective learning must steer a path between two pitfalls:

- the desire to copy a model that has demonstrated its excellence in a different context. While it is easy to transpose relatively vague managerial notions like the term "project 
management”, in practice they generally do not stand up well to the differences in the new context;

- rejection of the immensely valuable lessons learned from management sciences and experience, which are a relevant resource for stimulating and contributing to the learning needed for a creative response suitable to the situation.

Since the methodology of management researchers enables them to subject their corpus of theory to concrete experimentation, these researchers can be useful resources for avoiding these two pitfalls and finding the path towards the innovation practices of tomorrow's companies. The present study is one of many that take this approach.

\section{$\underline{\text { References }}$}

Bansard D., Cova B., Flipo JP. (1992), Le marketing de projets : de la réaction à l'anticipation, Recherche et Application en Marketing, vol. VII, n 4/92.

Ben Mammoud-Jouini S. (1998), Stratégies d'offre innovantes et dynamiques des processus de conception. Le cas des grandes entreprises françaises de bâtiment, Unpublished Phd Thesis, Ecole Polytechnique, France.

Boudès T. (1997), L’organisation de la préparation au changement dans les grandes entreprises dominantes menacées, Unpublished Phd Thesis, Ecole Polytechnique, France.

Brown S.L. \& Eisenhardt K.M. (1997), The art of continuous change : linking complexity theory and time-paced evolution in relentlessly shifting organizations, Administrative Science Quarterly, vol. 42, n 1.

Brown S.L. \& Eisenhardt K.M. (1998), Competing on the edge. Strategy as structured Chaos, Harvard Business School Press.

V. Chapel (1996), La croissance par l'innovation : de la dynamique d'apprentissage à la révélation d'un modèle industriel. Le cas Tefal, Unpublished Phd Thesis, Ecole Nationale Supérieure des Mines de Paris, France. 
F. Charue-Duboc, (1997), Maîtrise d'oeuvre , maîtrise d’ouvrage et direction de projet : des catégories pour comprendre l'évolution des fonctionnements en projet dans le secteur chimie de Rhône Poulenc, Gérer et Comprendre, n49.

Charue-Duboc F. (1998), The role of research departments in focusing innovative projects and understanding customer usage and needs, Proceedings of the International Research Network on Project Management and Temporary Organization (IRNOP Conference), Calgary, july 6-8.

Charue-Duboc F. \& Midler C. (1998), Renewing research management in project oriented organizations : the case of a global vaccine firm, Proceedings of the International Research Network on Project Management and Temporary Organization (IRNOP Conference), Calgary, july 6-8.

Clark K. \& Fujimoto T. (1991), Product development performance, Harvard Business School Press.

Cooper R G, Edgett S J et Kleinschmidt E J, Best Practices for Managing R\&D Portfolios, Research Technology Management, july August 1998.

Hatchuel A. (1999), Connaissances, modèles d'interaction et rationalisation, Revue d’Economie Industrielle, $n^{\circ} 88$.

Hatchuel A., Chapel V., Deroy X., Le Masson P., (1998), Innovation répétée et croissance de la firme, Rapport du programme « Enjeux économiques de l'innovation », Centre National de la Recherche Scientifique, Paris.

Kesseler A. (1998), The creative supplier, Unpublished Phd Thesis, Ecole Polytechnique, France.

Latour B. (1989), La science en action, Gallimard, Paris. 
Lenfle S., (1997), La gestion des projets d'innovation en amont des filières industrielles : l'exemple d’Usinor, Unpublished thesis, Ecole Nationale des Ponts et Chaussées, Paris.

Lamming R. (1993), Beyond Partnership : strategies for innovation and lean supply, Prentice hall, New-York

Lundin, R. A. \& Midler, (1998) C. Project as Arenas for Renewal and Learning Processes (eds) Kluwer Academic Publishers.

Lynn L.S., Morone J.G. \& Paulson A.S. (1996), Marketing and discontinuous innovation : the probe and learn process, California Management Review, vol. 38, n 3.

Michel, Salle \& Valla (1996), Marketing Industriel, Economica, Paris.

Midler C. \& al (1996), Du management de projet aux nouvelles rationalisations de la conception, Cahiers du Centre de Recherche en Gestion, Paris

Midler C. (1993), L’auto qui n’existait pas, InterEditions, Paris.

Nonaka I. \& Takeuchi H. (1995), The knowledge-creating company, Oxford University Press, New-York.

Schön D. (1983), The reflective practitioner. How professionals think in action, Basic Books, New-York.

Schön D. (1997), Apprentissage organisationnel et épistémologie de la pratique, in Les limites de la rationalité, Reynaud B. (eds), La Découverte, Paris.

Weil B. (1999), Conception collective, coordination et savoirs. Les rationalisations de la conception automobile, unpublished $\mathrm{PhD}$ thesis, Ecole Nationale Supérieure des Mines de Paris, Paris.

\footnotetext{
${ }^{1}$ This market accounts for $38 \%$ of the company's sales. Usinor is the European leader in steels for the auto industry.

${ }^{2}$ A $25 \%$ reduction in $\mathrm{CO}_{2}$ emissions by the year 2008 as part of the CAFE agreements.
} 


\footnotetext{
${ }^{3}$ This example clearly illustrates the dangers of allowing a new material to make a breakthrough. Besides the functional superiority of plastic, its use has occasionally even led to the dismantling of the facilities needed for using steel, making it almost impossible to re-employ it.

${ }^{4} \mathrm{~A}$ laser is used to weld together several sheets of different thicknesses and characteristics to constitute a blank of varying thickness, which is then pressed. This leads to a reduction in weight while ensuring improved performance at critical places.

${ }^{5}$ Given the large investments made both in mass production equipment and in the confirmation of solutions, manufacturers seek to avoid frequent changes in the choice of materials. It is thus particularly difficult to "reconquer" a component lost to plastics.

${ }^{6}$ Hydroforming makes it possible to produce automobile body parts (chassis side-members, engine cradle, A arm, etc.) using steel tubes in which water is injected at very high pressures (up to 4,000 bars). The tube is then pressed against a tool held closed by a press. This can be used to produce forms that could not be achieved by conventional stamping.

${ }^{7}$ On this point see the interesting work of Michel, Salle and Valla (1996).

${ }^{8}$ Usinor's goal was to set specifications and counsel others involved in the design. At no point did the company envisage selling hydroformed items. It restricts its role to supplying steel tubes along with knowledge about hydroforming them (simulation, tests, feasibility, estimates, etc.).

${ }^{9}$ Potential for deformation in the hydroforming process? Which steels are most suitable? How should the process be simulated? etc.

${ }^{10}$ We should specify that these studies can be different in nature. Some, very exploratory, correspond to category II in Table 1 (e.g. the use of hydroforming in automobile designs in the period 2005-10). In other cases, innovation can provide a new response to long-standing, well-defined questions (hydroforming for an engine cradle with given characteristics).

${ }^{11}$ Interview with a researcher, CED Montataire, January 1999.
} 